\title{
Saturation flow mathematical model based on multiple combinations of lane groups
}

\author{
Ilie Dumitru \\ Assoc. Prof., University of Craiova, Faculty of Mechanics, Romania \\ Lucian Matei \\ Assist. Prof., University of Craiova, Faculty of Mechanics, Romania \\ Laurentiu Racila \\ Assoc. Prof., University of Craiova, Faculty of Mechanics, Romania \\ Dumitru Nicolae \\ Prof., University of Craiova, Faculty of Mechanics, Romania
}

\begin{abstract}
The ideal value of the traffic stream that can pass through an intersection is known as the saturation flow rate per hour on vehicle green time. The saturation flow is important in the understanding of the traffic light cycle and from there the understanding the Level of Service. The paper wishes to evaluate through a series of applied mathematical methods the effect of different lane grouping and critical lane group concept on the saturation flow rate. The importance of this method is that it creates a base for a signalized intersections timing plan.
\end{abstract}

\section{INTRODUCTION}

The signalized intersection is the most complex location [1]. There are five fundamental concepts used in signalized intersection analysis methodology and these are:

- The critical lane group concept

- The $\mathrm{v} / \mathrm{s}$ ratio as a measure of demand

- Capacity and saturation flow rate concepts

- Level-of-service criteria and concepts

- Effective green time and lost-time concepts

The paper wishes to present a methods for applied mathematics that will undertake the first three concept enumerated above.

\subsection{Saturation Headway}

The constant headway achieved is referred to as the saturation headway, as it is the average headway that can be achieved by a saturated, stable moving queue of vehicles passing through the signal [2]. Given that the saturation flow rate can be multiplied by the number of lanes provided for a given set of movements to obtain a saturation flow rate for a lane group or approach.

\subsection{Critical lane group}

Critical-lane analysis compares actual demand flows in a single lane with the saturation flow rate and capacity of that lane. Critical-lane group analysis compares actual flow with the 
saturation flow rate and capacity. Where several lanes operate in equilibrium the lane group is treated as a single entity $[1,3]$. Whether individual lanes or lane groups are used, the mathematic model ensures that the ratio of $v$ to $c$ based on an individual lane is equal to the ratio of $v$ to $c$ of the entire lane group.

\section{$1.3 v / s$ ratio}

To obtain a single parameter that will allow the intensity of demand in each lane group to be compared directly, the demand flow rate, $\mathrm{o}$, is divided by the saturation flow rate, $\mathrm{s}$, to form the "flow ratio," Since the prevailing conditions in each lane group are reflected in both the flow rate and the saturation flow rate values [3, 4].

\section{SATURATION FLOW RATE}

In the Saturation Flow Rate, a base saturation flow rate is modified by a series of multiplicative adjustment factors to determine the total saturation flow rate for each lane group under prevailing demand conditions. It is in this formula for the best accuracy the model permits left-turn movements $[2,5]$. The saturation flow rate for a lane group is estimated as:

$$
s=s_{0} \cdot N \cdot f_{W} \cdot f_{H V} \cdot f_{g} \cdot f_{p} \cdot f_{b b} \cdot f_{a} \cdot f_{L U} \cdot f_{L T} \cdot f_{R T} \cdot f_{L T p} \cdot f_{R T p}
$$

where:

- $\mathrm{s}=$ saturation flow rate for the lane group

- $\mathrm{s}_{0}=$ base saturation flow rate

- $\mathrm{N}=$ number of lanes in the lane group

- $\mathrm{f}=$ adjustment factor for prevailing condition ( $\mathrm{w}=$ lane width; HV = heavy vehicles; $\mathrm{g}=$ grade; $\mathrm{p}=$ parlung; $\mathrm{bb}=$ local bus blockage; $\mathrm{a}=$ area type; $\mathrm{LU}=$ lane use; $\mathrm{RT}=$ right turn; $\mathrm{LT}=$ left turn; $\mathrm{Rpb}=$ pedestrian/bicycle interference with right turns; and $\mathrm{Lpb}=$ pedestrian/bicycle interference with left turns)

\subsection{Lane grouping model}

This methodology assumes that the studied intersection is of maximum of four entrances and of a maximum of three lanes / entrance. The mathematical model uses combination to calculate and display the possible combinations of lane groups and in the same time discard all the combinations that are in the same configuration $[4,6]$.

The calculation is based on three stages: combinations of all entrances taken by 2, 3 and 4 as seen in the figure 1 . Then the model combines all the possibilities starting from the first given combination to the last as in the figure 2. Is important to mention that in this stage the model combines only the values from the direction Nord and South and then East and West (figure 3). This is done because of the movement conflicts that are considered to be critical in any other combination and so it can't be achieved in real life [6, 7].

The next step of the model is to combine Nord, South East and West direction lane groups calculated above in an all-purpose matrix so that all the calculation for the saturation flow rates can be done on it, as it is shown in figure 4. 


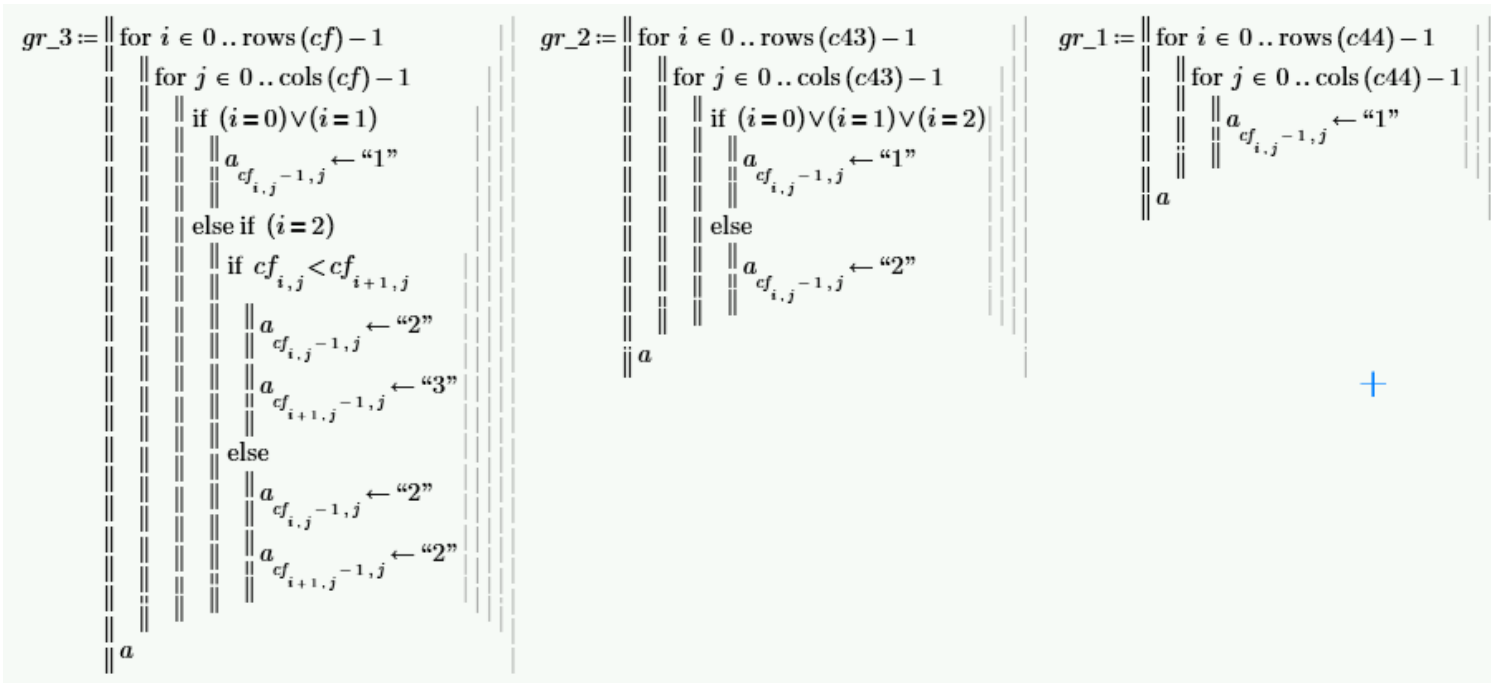

Fig. 1 - Calculation of all the combinations of all entrances

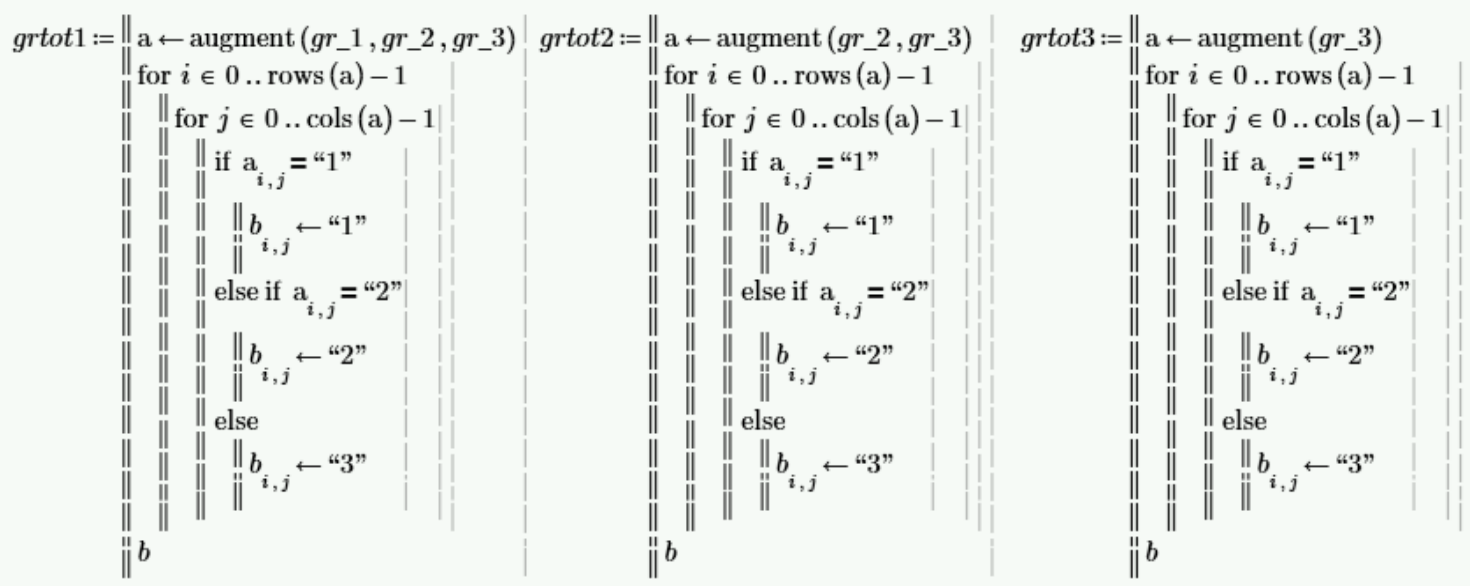

Fig. 2 - Augmentation of all the possible solution from the combinatory phase

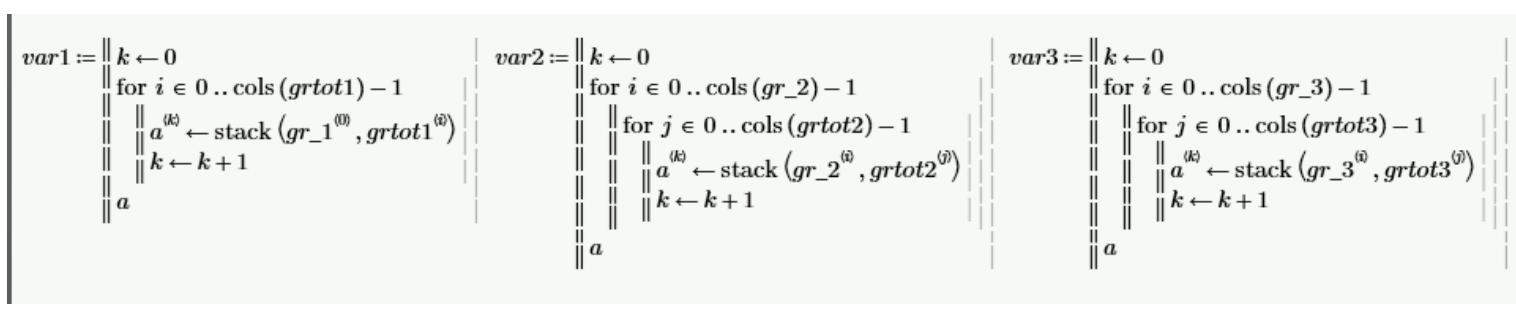

Fig. 3 - Calculation for all Nord, South East and West directions

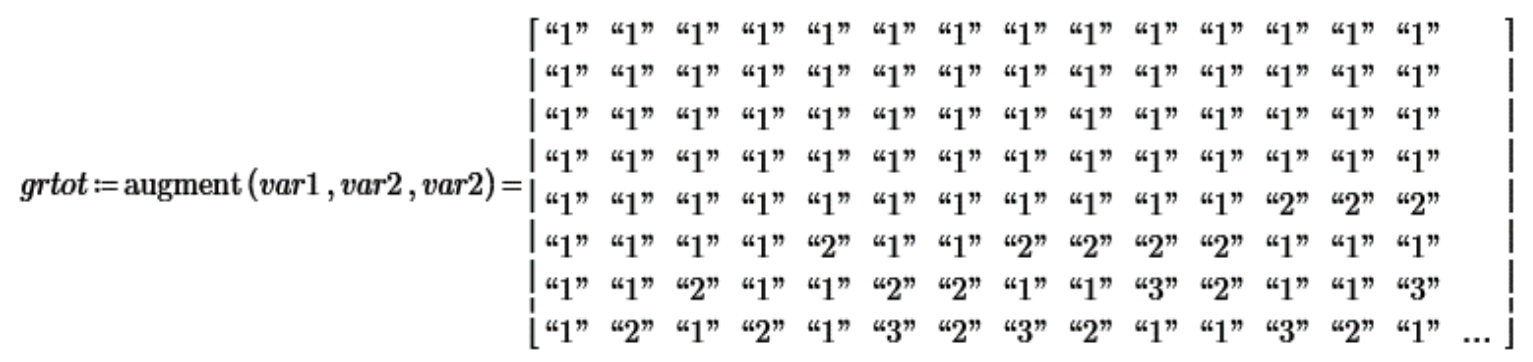

Fig. 4 - Augmentation of all the possible lane grouping in one matrix 
The mathematical model divides the matrix in 2 zones one for the Nord and South the first four rows and one East and West the last four rows. After the distribution of the zones the model creates another distribution based on the possible lane groups and allocates them with numbers from 1 to 3 because on a cardinal zone there can be only 3 ways of grouping the lanes and movements in the lanes.

\subsection{Saturation Flow calculation}

As mentioned above the saturation flow is modified by a series of multiplicative adjustment factors for each lane group under prevailing demand conditions. The conditions / factors are the following: $\mathrm{w}=$ lane width; $\mathrm{HV}=$ heavy vehicles; $\mathrm{g}=$ grade; $\mathrm{p}=$ parlung; $\mathrm{bb}=$ local bus blockage; $\mathrm{a}=$ area type; $\mathrm{LU}=$ lane use; $\mathrm{RT}=$ right turn; $\mathrm{LT}=$ left turn; $\mathrm{Rpb}=$ pedestrian/bicycle interference with right turns; and $\mathrm{Lpb}=$ pedestrian/bicycle interference with left turns [2, 3].

For each of them it is important to mention that are calculated based on the matrix calculated above. All these factors differ from a configuration of lanes to another so it is important to evaluate all the possibilities and the mathematical model comes in support so that the calculation are done in accordance with all the possible combinations.

The first step in the factor calculation is to create a support database that will contain information about each constant variable in the mathematical model like: numbers of vehicles, lane width, number of pedestrians, slope degree, etc. as seen in the figure 6 .

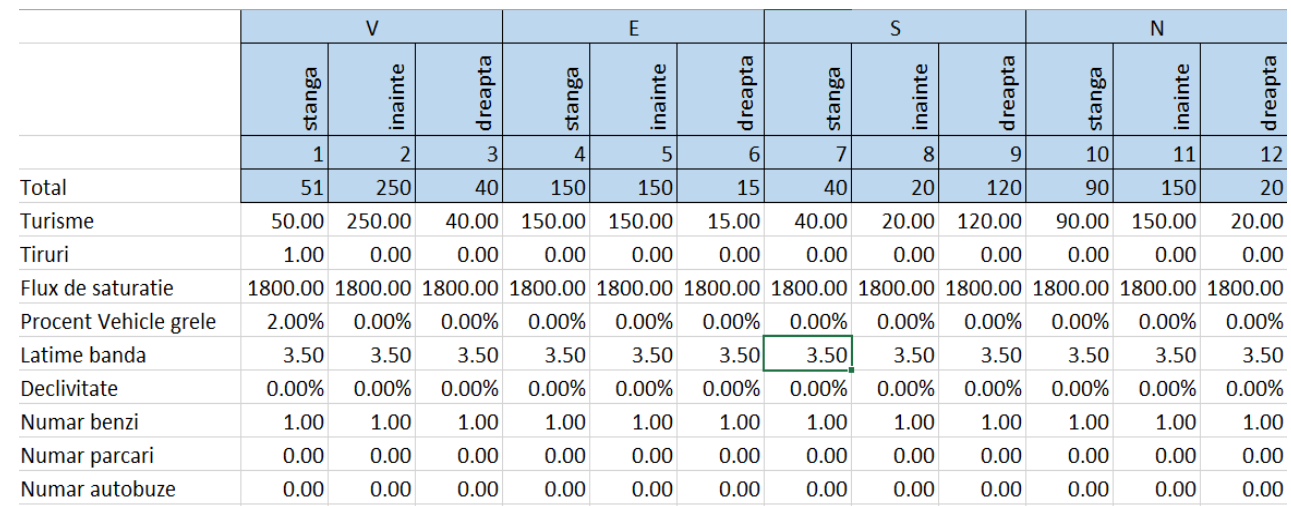

Fig. 5 - Constant variable definition

The next step is calculate all the constant based on the current intersection condition and geometry (figure 6, 7 and 8).

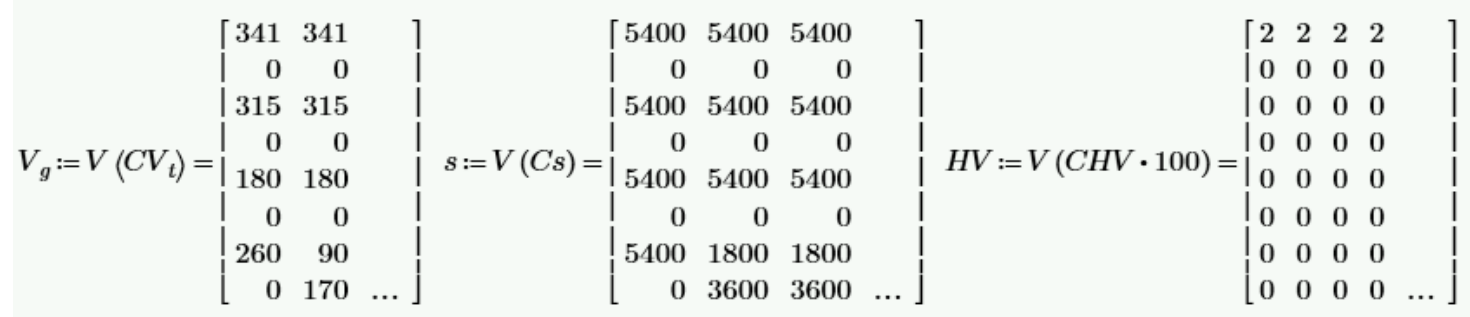

Fig. 6 - Calculation of traffic volume, base saturation and heavy vehicles percent 


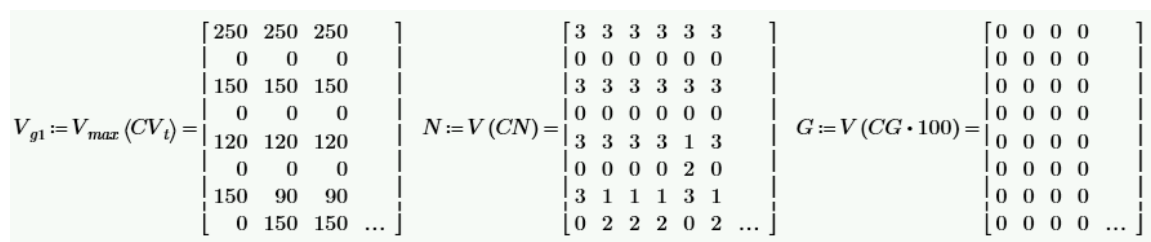

Fig. 7 - Calculation of lane group volume, number of lanes and declivity

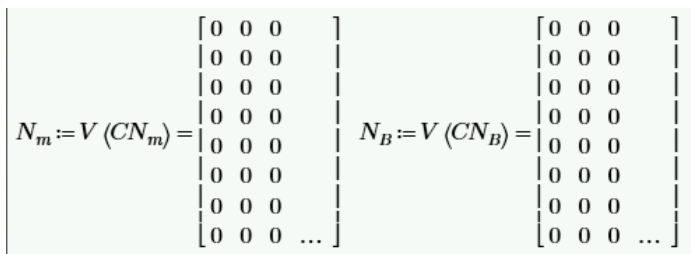

Fig. 8 - Calculation of number of parked vehicles and bus stops

The calculation of the saturation flow factors in the mathematical model will use all the parameters calculated above in the figure 5. The calculation is done on the bases of the lane grouping matrix and can be seen in the figure 9, 10 and 11.
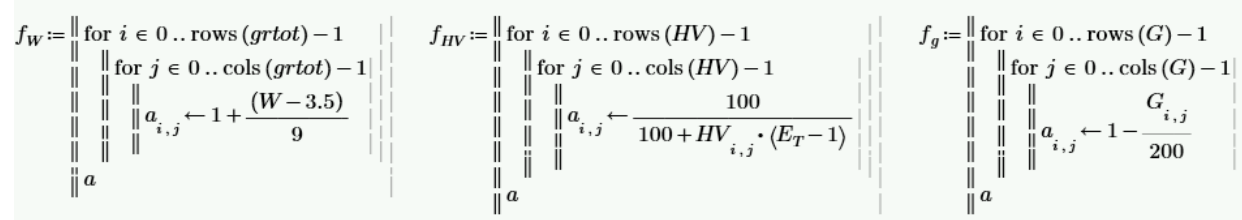

Fig. 9 - Calculation of firs three factors of the saturation flow
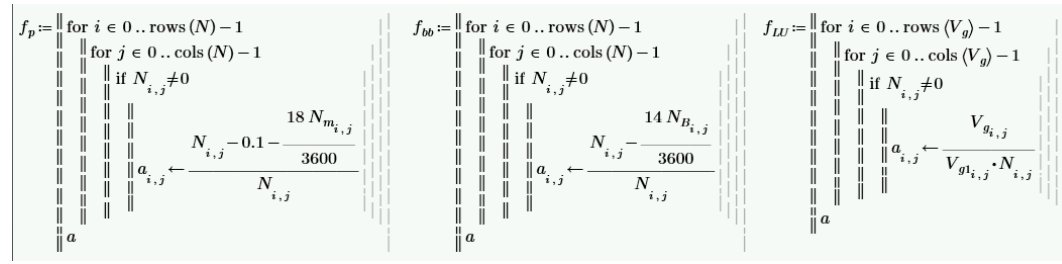

Fig. 10 - Calculation of busses stops, parking and lane utilization factors
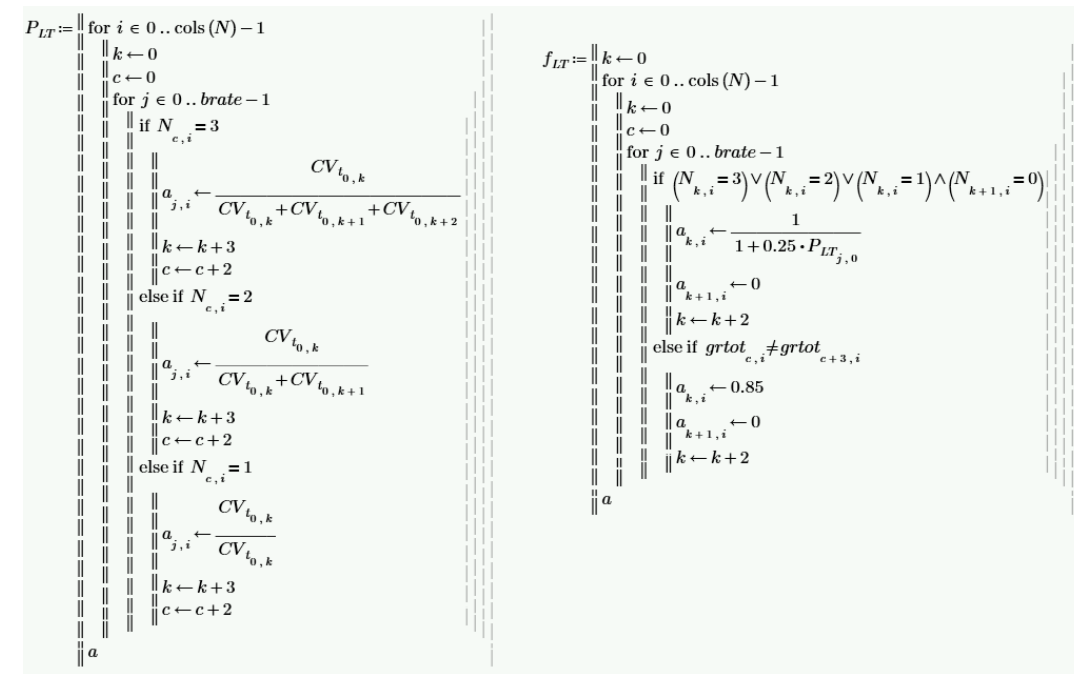

Fig. 11 - Calculation of left turn adjustment factor 


\section{CONCLUSION}

The matrix type calculation of the saturation flow model for every type of lane groups in the studied intersection is important through multiple aspects like the following:

- The lane grouping in an intersection can be changed for the same conditions based on the wanted traffic signal plan and future growth of the vehicles passing through. The model can be used to evaluate multiple situations in the same time and see what configuration of lanes can better be used for the studied intersection

- Usually a day is divided in 4 frames: morning rush hour, normal traffic condition, midday rush hour and the final normal traffic condition which usually last until morning. Because of this the traffic signal plan is calculated based on one of the above frames. The mathematical model created is important because it can be used to evaluate the different traffic conditions from all 4 frames in relation with all the lane grouping and in the same time can be used to make an evaluation of the best possible lane group usage based on traffic condition of the day.

- The simplest way to coordinate a road section is through a green wave. The simple calculation of the green wave forces us to maintain in general the same configuration (in some upper and lower limits) of the signal plan and lane configuration. Because of this it is difficult to evaluate multiple lane configuration on multiple intersections because of the quantity of calculus that needs to be done. The model created can evaluate in the same time all the lane groups in all the intersection and so given us the possibility to evaluate in a split second the best lane configuration that can be applied to all the intersection in the same time.

\section{REFERENCES}

[1] C.M. Andrews, S.M. Elahi, J.E. Clark, Traffic-Control System In Transportation Research Record, pp. 150-155, 1998.

[2] G.P. Box, G. Jenkins, G. Reisel, Time Series Analysis: Forecasting and Control. Prentice Hall, Englewood Cliffs, NJ, 1994.

[3] D. I. Robertson, R. D. Bretherton, “Optimizing Networks of Traffic Signals in Real Time - The SCOOT Method," IEEE Transactions on Vehicular Technology, Vol. 40, No. 1 (February 1991).

[4] J. A. Stewart, M.V. Aerde, An Assessment of Adaptive Co-ordination of Traffic Signal offsets within integration, Traffic Engineering and Control, Volume 39, 1998.

[5] Transportation Research Board, American Association of State Highway and Transportation Officials (AASHTO) and Federal Highway Administration Highway, Capacity Manual 2010, 2010.

[6] Dumitru I., Matei L., Vinatoru M., Racila L., Oprica Th., Aspects Regarding Priority Settings in Unsignalized Intersections and the Influence on the Level of Service, Proceedings of the European Automotive, Congress EAEC-ESFA 2015, Springer International Publishing Switzerland 2016

[7] S. Puntanen, The effect of layout change at intersections on traffic behavior - bicycle crossings, VTT Technical Research Centre of Finland, 1996. 